\title{
Introducing selenium in single component molecular conductors based on nickel bis(dithiolene) complexes
}

Hadi Hachem, ${ }^{a}$ HengBo Cui, ${ }^{\mathrm{b}}$ Reizo Kato, ${ }^{\mathrm{b} *}$ Olivier Jeannin, ${ }^{a}$ Frédéric Barrière, ${ }^{a}$ Marc Fourmigué $^{\star a}$ and Dominique Lorcy*a

${ }^{\text {a } U n i v ~ R e n n e s, ~ C N R S, ~ I S C R ~(I n s t i t u t ~ d e s ~ S c i e n c e s ~ C h i m i q u e s ~ d e ~ R e n n e s) ~-~ U M R ~ 6226, ~ F-35000 ~}$ Rennes, France; Email: dominique.lorcy@univ-rennes1.fr ; Email: marc.fourmigue@univrennes1.fr

${ }^{\mathrm{b}}$ Condensed Molecular Materials Laboratory, RIKEN, Wako-shi, Saitama 351-0198, Japan, Email: reizo@riken.jp

Supplementary Information 

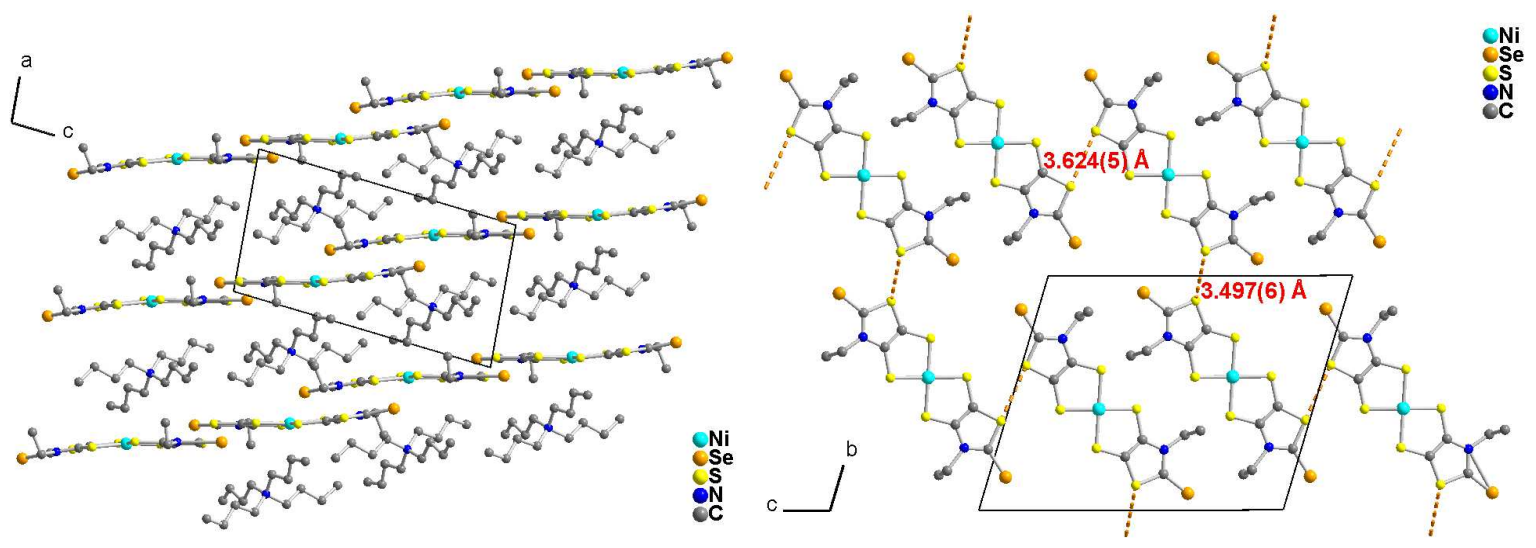

Figure S1. Layered solid state organization of [NBu 4$]\left[\mathrm{Ni}(\text { Et-thiazSedt })_{2}\right] . \mathrm{H}$ atoms were omitted for clarity.
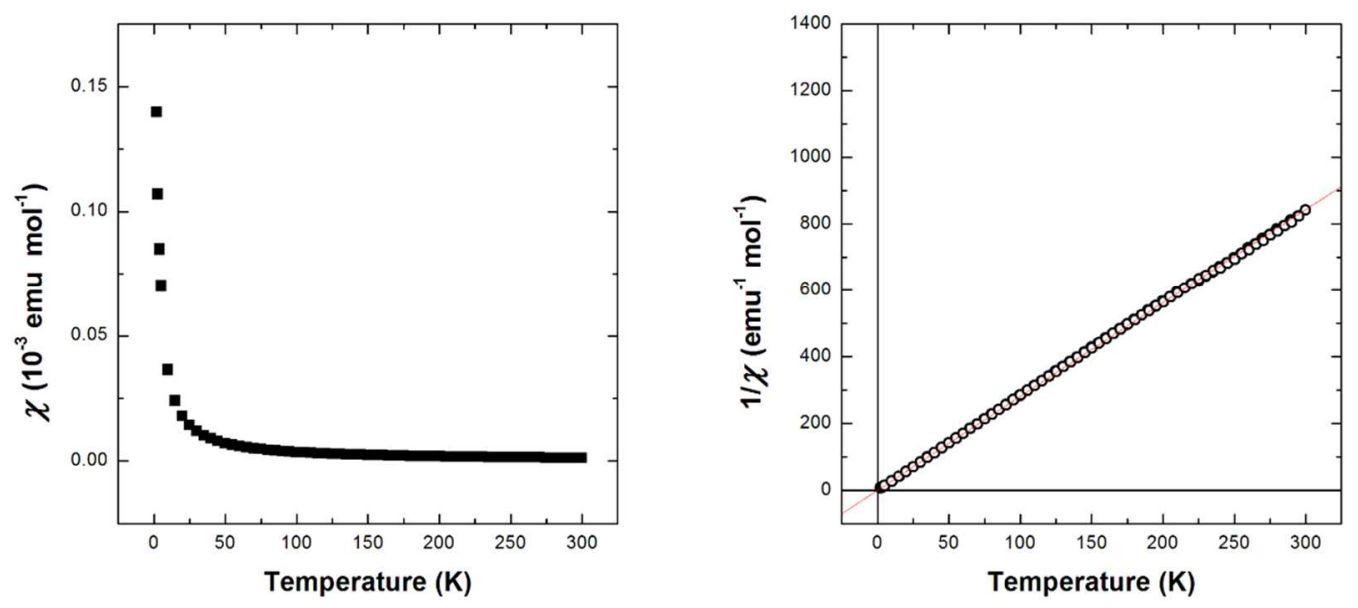

Figure S2 Temperature dependence of the magnetic susceptibility (left) and $1 / \chi v s$. T with Curie-Weiss fit (red line) (right) for $\left[\mathrm{NBu}_{4}\right]\left[\mathrm{Ni}\left(\right.\right.$ Et-thiazSedt) $\left.{ }_{2}\right]$. 

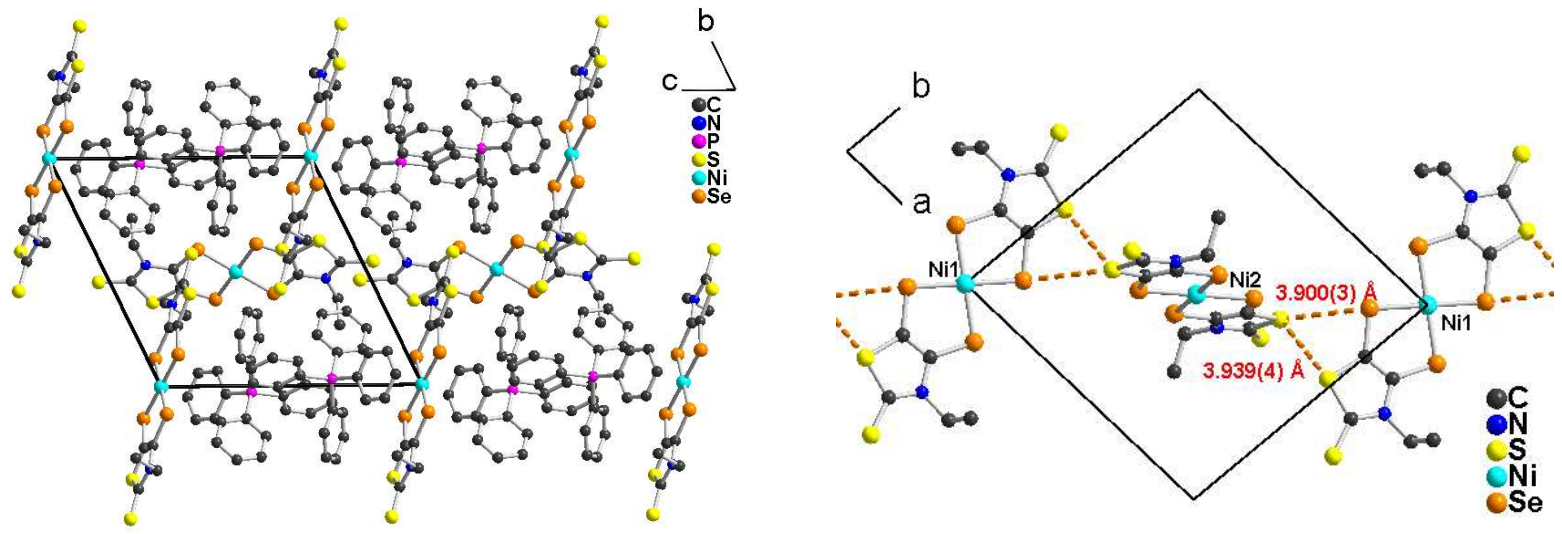

Figure S3. Left: Projection along the $a$ axis of two unit cells of [ $\left.\mathrm{PPh}_{4}\right]\left[\mathrm{Ni}(\mathrm{Et}-\text { thiazds })_{2}\right]$ showing the limited intermolecular interactions between radical anion species. Right: Detail of the shortest (but long) chalcogen •••chalcogen contacts. H atoms were omitted for clarity.

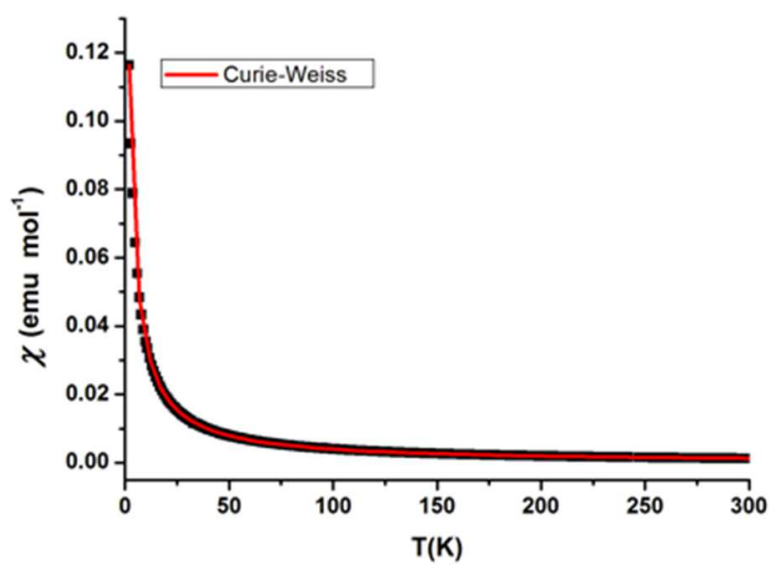

Figure S4. Left: Temperature dependence of the magnetic susceptibility of $\left[\mathrm{Ph}_{4} \mathrm{P}\right][\mathrm{Ni}(\mathrm{Et}-$ thiazds) $)_{2}$ ] with (in red) fit to Curie-Weiss law (See text). 

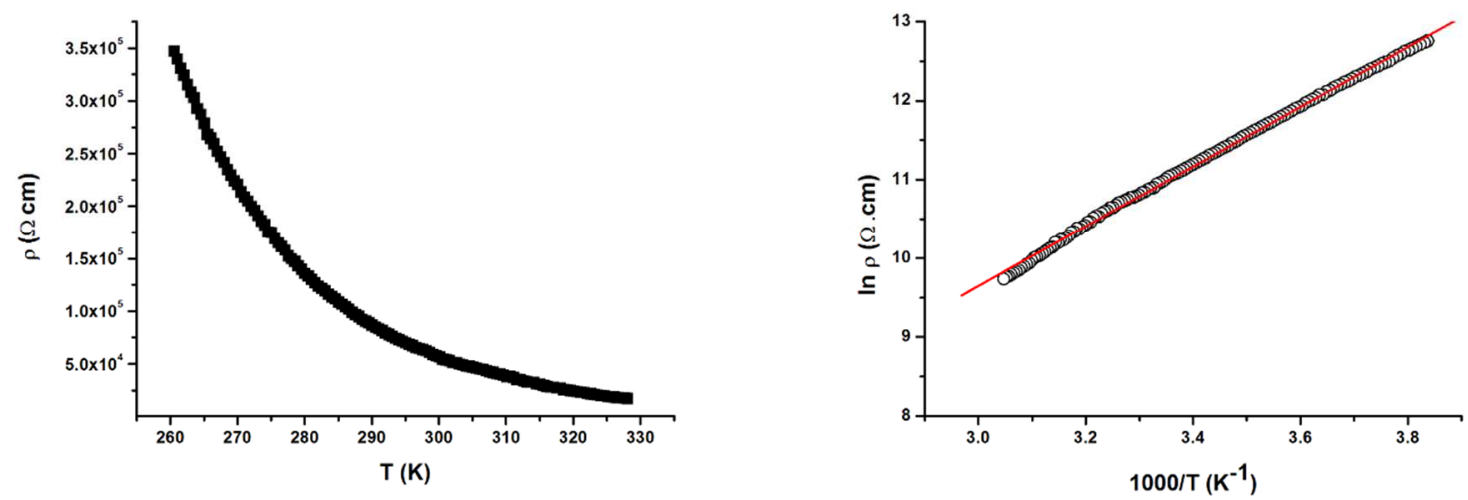

Figure S5. Temperature dependence of the resistivity of [Ni(Et-thiazSedt $)_{2}$ ]. Due to the small size of the crystals, the transport measurement was performed on two points.

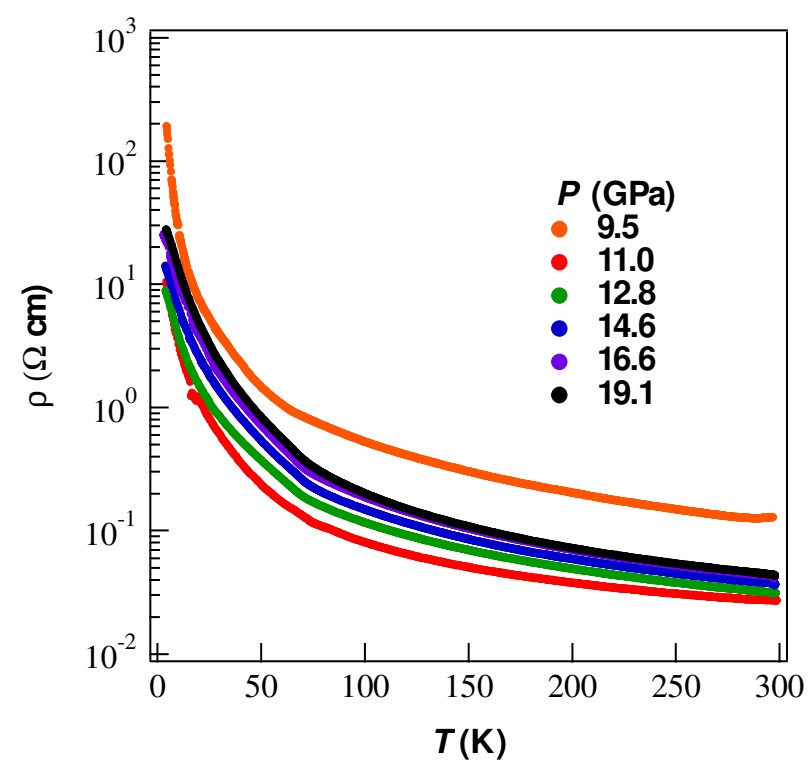

Figure S6. Temperature dependence of the resistivity of $\left[\mathrm{Ni}(\text { Et-thiazds })_{2}\right]$ as a function of pressure determined on sample 3 between 9.5 and $19.1 \mathrm{GPa}$. 


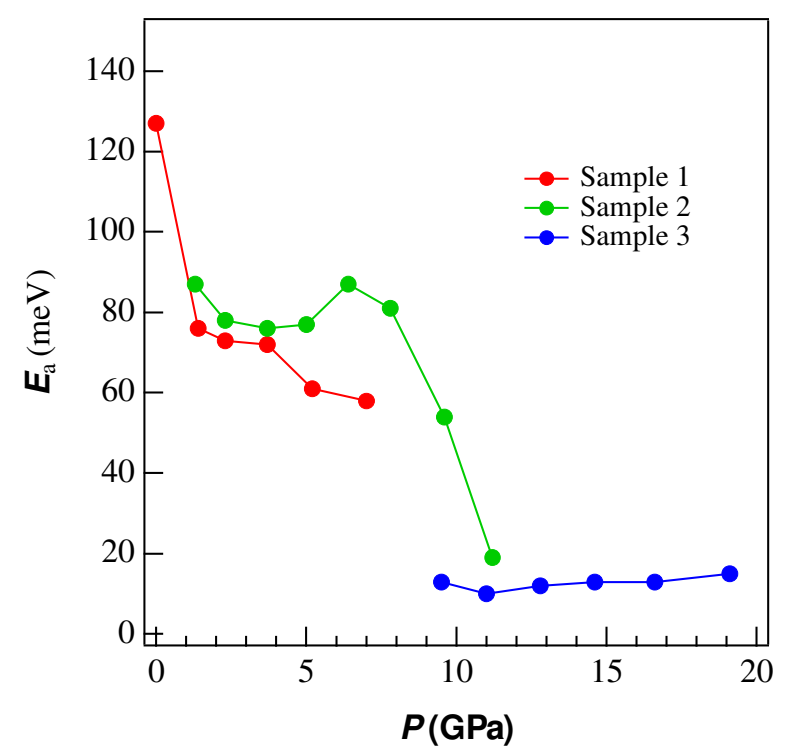

Figure S7 Evolution of the activation energy of the resistivity for the three samples
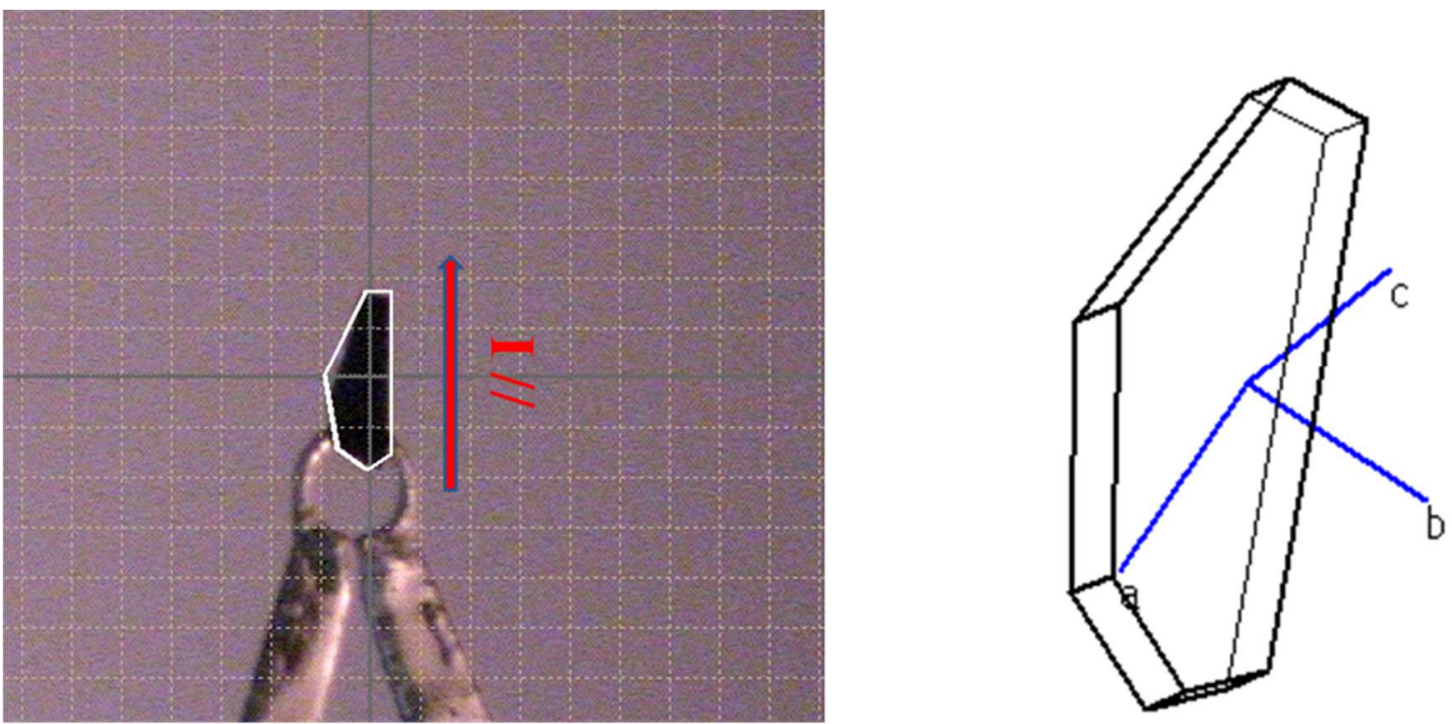

Figure S8. Orientation of the crystal of $\left[\mathrm{Ni}(\text { Et-thiazds })_{2}\right]$ for transport measurments 
Table S1. Exponents, contraction coefficients, and atomic parameters used in band structure calculations

STO Ni 4s. 4p. 3d.

$-9.1700001 .8250001 .00000$

$-5.1500001 .1250001 .00000$

$-13.4900005 .7500000 .5683002 .0000000 .629200$

STO S 3s. 3p.

-20.000000 2.6620000.5564001.6880000.487300

$-13.3000002 .3380000 .5212001 .3330000 .544300$

STO Se $4 \mathrm{s.} 4 \mathrm{p}$.

-20.500000 3.1387000 .6162501 .8899600 .512890

$-13.2000002 .7150400 .5508901 .5114000 .572150$

STO C 2s. 2p.

-21.4000001.6250001.00000

$-11.4000001 .6250001 .00000$

STO H 1s.

$-13.6000001 .3000001 .00000$

STO N 2s. 2p.

-26.0000001.9500001.00000

$-13.4000001 .9500001 .00000$ 


\section{Computational details}

Full geometry optimization was performed with Density Functional Theory ${ }^{1}$ using the hybrid Becke-3 parameter exchange functional ${ }^{2}$ and the Lee-Yang-Parr nonlocal correlation functional $^{3}$ (B3LYP) implemented in the Gaussian 09 (revision D.01) program suite and using the LANL2DZ basis set. ${ }^{4}$ Gaussview 5.0 was used to generate the figures.

Optimized cartesian coordinates for $\left[\mathrm{Ni}(\text { Et-thiazSedt })_{2}\right]$ and its dimer, and the sulfur analogue $\left[\mathrm{Ni}(\text { Et-thiazdt })_{2}\right]$ are provided separately as a single XYZ text file in a format for convenient visualization.

[1] (a) Hohenberg, P.; Kohn, W. Inhomogeneous Electron Gas. Phys. Rev., 1964, 136, B864. (b) Parr, R. G.; Yang, W. Density-Functional Theory of Atoms and Molecules; Oxford University Press: Oxford, U.K., 1989.

[2] (a) Becke, A. D. Density-functional exchange-energy approximation with correct asymptotic behavior. Phys. Rev. A, 1988, 38, 3098. (b) Becke, A. D. A new mixing of Hartree-Fock and local density-functional theories. J. Chem. Phys., 1993, 98, 1372. (c) Becke, A. D. Density-functional thermochemistry. III. The role of exact exchange. $J$. Chem. Phys., 1993, 98, 5648.

[3] Lee, C.; Yang, W., Parr, R. G. Development of the Colle-Salvetti correlation-energy formula into a functional of the electron density. Phys. Rev. B, 1988, 37, 785.

[4] (a) Wadt, W. R.; Hay, P. J. Ab initio effective core potentials for molecular calculations. Potentials for main group elements Na to Bi. J. Chem. Phys., 1985, 82, 284. (b) Hay P. J.; Wadt, W. R. Ab initio effective core potentials for molecular calculations. Potentials for K to Au including the outermost core orbitals. J. Chem. Phys., 1985, 82, 299. 


\section{Structure of the Ni(Et-thiazSedt) ${ }_{2}$ dimer}

\section{Calculated (DFT B3LYP/LanL2DZ)}

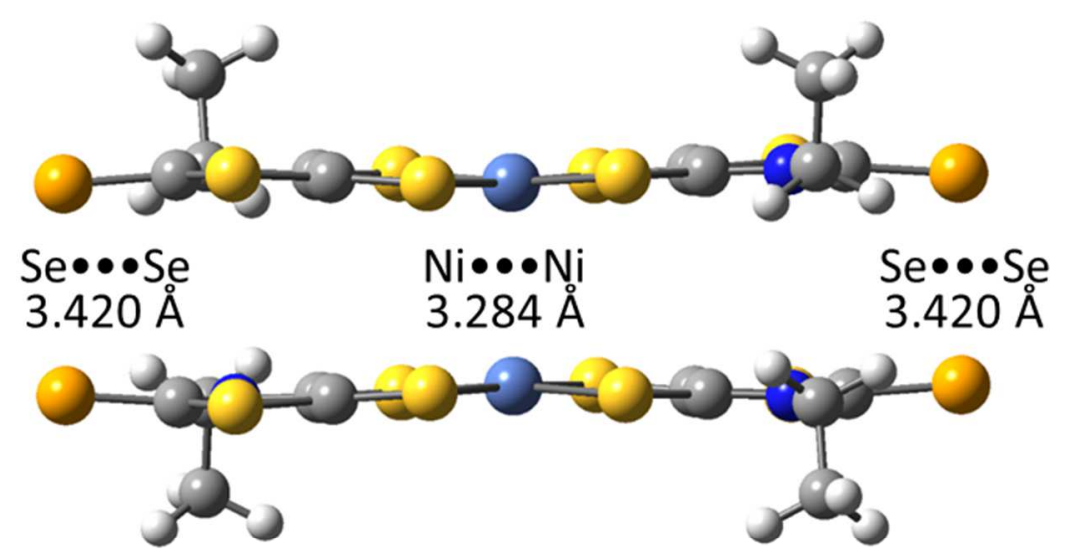

Short $\mathrm{H} \bullet \bullet \mathrm{H}$ contacts (from left to right) $2.844502 .688152 .68722 \quad 2.84481 \AA$
X-ray crystal structure

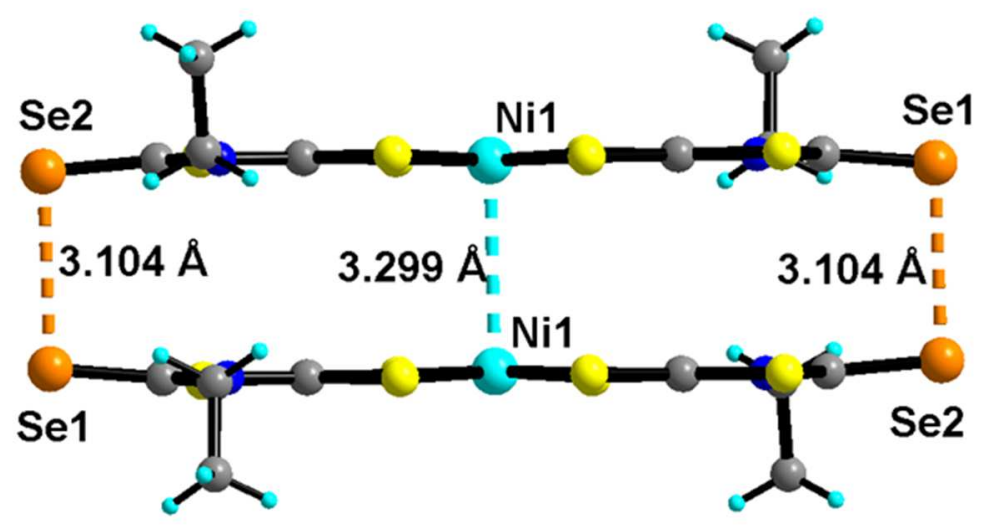

Short $\mathrm{H} \bullet \bullet \mathrm{H}$ contacts (from left to right) 2.743(5) 2.716(5) 2.716(5) 2.743(5) A

Figure S9. Details of the structure of the $\left[\mathrm{Ni}(\text { Et-thiazSedt })_{2}\right]$ dimer calculated (left) and experimentally determined (right) 


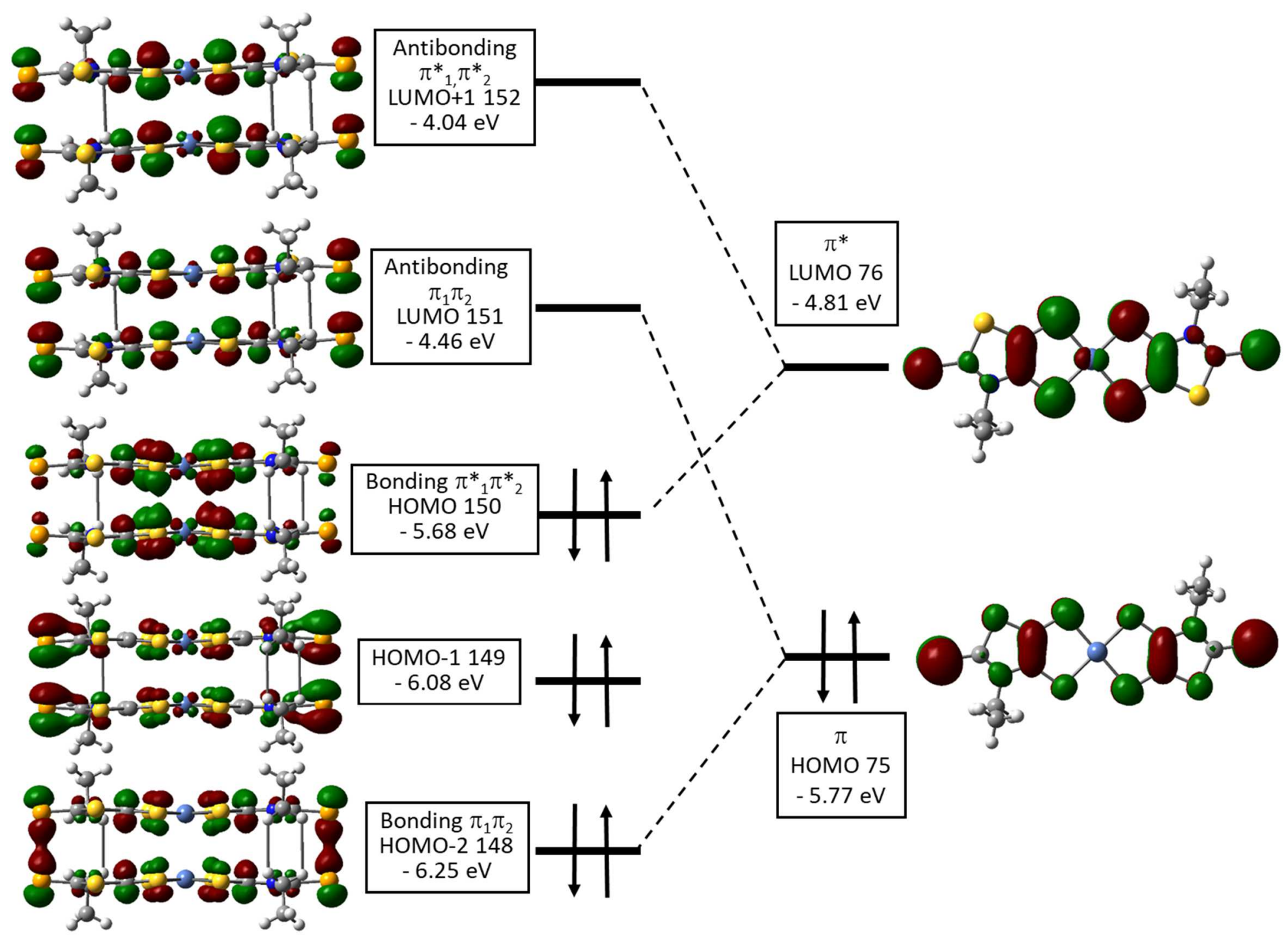

Figure S10 Sketch of the frontier molecular orbitals for the $\left[\mathrm{Ni}\left(\mathrm{Et}(\text { thiazSedt })_{2}\right]\right.$ dimer (left) and the monomer (right) drawn with a cutoff of 0.03 $\left[\mathrm{e} / \mathrm{bohr}{ }^{3}\right]^{1 / 2}$. 